\title{
Virtual Reality Technology in Higher Vocational Education "China Tourism Geography" Teaching Application
}

\author{
Jiang Ge \\ Chengdu Polytechnic \\ Sichuan, China \\ E-mail:171735597@qq.com
}

\author{
Lai Bin \\ Chengdu Polytechnic \\ Sichuan, China \\ E-mail:2220285867@qq.com
}

\begin{abstract}
In view of the existing virtual reality technology (VRT) used in the process of problems, such as: teachers lack of awareness of the use of virtual reality technology, virtual reality technology features the use of low efficiency, virtual reality technology and the reform of classroom teaching integration, to illustrate the proposed method and the way to solve the problem. The author puts forward the constructive opinions of teaching content presentation mode, teaching method reform and teaching practice training, and puts forward the means and methods for the application of virtual reality technology in the teaching of higher vocational colleges. On the basis of this, the paper puts forward a new idea of teaching reform.
\end{abstract}

Keywords-Virtual Reality Technology, Chinese Tourism Geography, Teaching Method Reform, Teaching Practice

Virtual Reality (VR) is a three-dimensional dynamic visual environment that uses computer technology to generate a simulation world, and the operator will have an immerse sense of presence. This technology is the end of the 20th century the rise of a comprehensive information technology, so that participants can use the habit of human perception of the virtual world, which greatly promoted the vitality of human-computer interaction. Higher vocational education revolves around the cultivation of students' ability, while vigorously carrying on the reform of education and teaching, how to use virtual reality technology to serve the reform of curriculum and teaching mode is the subject that we should think and study.

\section{I. "ChINA TOURISM GEOGRAPHY" COURSE INTRODUCTION}

The "Chinese Tourism Geography" is the study of human tourism activities and relationship between geographical environment and social economic development of emerging disciplines. Main research tourist geography background and space behavior characteristics; The emergence, development and evolution of the tourism resources of geographical environment and the spatial distribution of tourism resources, as well as the impact of tourism, tourist capacity, development of tourism planning, etc.

\section{The Virtual ReAlity TeChNOLOGY In the TEACHING OF THE EXISTING PROBLEMS}

(1)On the basis of virtual simulation technology teaching reform core in the teacher, only the teacher's ideology in place, in order to independently explore and discover the unlimited use of software potential, if teachers follow the beaten track or in front of modern information afraid of difficulties, then the best equipment Is a high-level furnishings.

(2)Reform of teaching method based on virtual simulation technology, focus on student ability training as the standard, to have a fundamental change in teaching concept, teaching reform is not grandstanding, the effectiveness of any reform is not see "stage effect", but to have a look at our knowledge objects -- students, whether in the reform than before more progress, otherwise the more advanced equipment is more advanced "blackboard".

(3)The virtual simulation technology-based teaching reform key In the virtual simulation technology proficient use, many schools of virtual simulation teaching system is basically exhibits, only when there are large-scale activities to visit the opening, so that the system has become a cake On the cream, just a dotted. In order to truly integrate the virtual simulation system and classroom teaching, the key is two fusions, namely the integration of classroom control technology and virtual simulation technology, the integration of modern educational philosophy and modern information technology development concept.

\section{ON THE BASIS OF THE VIRTUAL REALITY TECHNOLOGY IN THE "ChInA TOURISM GEOGRAPHY" COURSE TEACHING CONSTRUCTIVE THINKING}

\section{A. Virtual reality technology to promote the presentation of teaching content reform}

"China Tourism Geography" subject covers many areas of human vision can't reach, or the geological phenomenon occurred in ancient times has disappeared and the historical landscape. The teacher alone can't explain to students to present a specific vivid image. The introduction of virtual reality technology in tourism geography teaching will be able to these scenes and faces vividly presented in front of students, the teaching effect than the traditional teaching methods are much better. 


\section{1) The tourism geography abstract problem intuitive presentation}

For some of the difficult needs of dynamic presentation of the knowledge, virtual reality technology can achieve the traditional teaching methods can't be achieved. For example, the Dujiangyan Irrigation Project is an example of learning the ancient water conservancy project. The core of the Dujiangyan Water Conservancy Project is to solve the "cornering circulation" of the sediment problem, and the teachers in the course of teaching are basically through the plane. The most important advantage of virtual simulation technology is to break through the language description, graphics, video and other traditional methods of physical limitations, through computer-related technology to achieve three-dimensional simulation, and its intuitive presentation of "cornering circulation" principle to indicate that each time the degree of understanding of students can reach more than $90 \%$.

2) With virtual reality technology for tourism planning project learning

Tourism planning, including tourism product development, quality of tourism services, tourism and cultural construction, tourism image promotion, tourism infrastructure and public service facilities and the promotion of measures such as the content, according to tourism development planning, the local people's governments above the county level can compile priorities Tourism resources development and utilization of special planning, specific areas of tourism projects, facilities and services supporting special requirements.

Traditional tourism planning and design in the quasi-three-dimensional performance level, that is, through the planning and design plans, renderings or sand table and other display planning and design results. In the planning and design of the scenic spot, the digital scenic spot will use the virtual reality technology in it. The planning and design can be used in a virtual three-dimensional environment in dynamic interactive way to carry on the immerse view of the future scenic spot. This is the traditional planning and design effects map and the default path of the three-dimensional animation can't be achieved.

Advanced virtual electronic sand table technology is easier to maintain and manage than the traditional sand table, can be easily modified, replaced, added, so saving costs; improve learning efficiency and so have a great advantage.

3) The use of virtual reality technology to reproduce the disappearance of technology

Virtual reality technology, 3D visualization platform to achieve the true reconstruction of architectural form, the ancient Chinese architectural components of many, clever and scientific wooden frame structure to create the external shape of the building, the unique tenon structure to enhance the seismic resistance of buildings, architecture Showing strict standardization, stylization, and attention to the construction of the group layout.

Learning ancient Chinese architecture can be virtual reality technology to demonstrate the architecture process, and embody the essence of ancient Chinese architecture of the brackets for detailed demolition and assembly, clear and intuitive to show the ancient architectural style.

In the aesthetic aspects of architecture can also make the observer as in reality, like browsing, immerse sense. At the same time, you can also choose different angles to observe, for example, can choose to watch the angle when walking can also be viewed in accordance with the angle of flight, you can also quickly locate the function you want to watch the location, very easy to achieve in reality can't quickly observe the operation of different locations, which brings a lot of learning and training facilities.

\section{B. Virtual reality technology to promote the reform of teaching methods}

We talked about the virtual simulation technology based on the core of the reform of teaching methods in the teacher, if teachers follow the beaten track, exclusion of new things, or with modern information technology with fear, it is difficult to take the initiative to explore modern information technology in teaching methods.

In this paper, the ancient town of rural tourism as an example illustrates how virtual reality technology to promote classroom teaching reform. Ancient town and rural tourism is a "Chinese tourism geography" courses involved in a teaching session, in the modern service industry under the guidance of highly skilled personnel training model, the overall consideration of the reconstruction of teaching content, stress from the work requirements of core competencies, training students' knowledge and skills of the coordinated development of employment to enhance the ability of students to enhance and serve the purpose of the local economy. Therefore, the teaching process uses the virtual simulation teaching system and the mobile terminal APP to realize the learning. By using the virtual simulation teaching system interface function, the multimedia environment interface is reserved on this system, and can be linked to other multimedia systems in the virtual simulation system. A large number of video, audio, real pictures, electronic documents, pictures, text materials to vivid interactive multimedia form of display, the system reflects a strong expansion. Using the form of a hyperlink, just a little with the mouse, you can call up the required information. The teacher led the students in the real scene with the mobile phone APP software track record, Path is the former Facebook employees, Dave Morin, Shawn Fanning and Dustin Mierau to create a private picture sharing application, the design philosophy is to provide users with a close friend Between the photos, mood, address and other information sharing mobile phone applications, the application of the biggest features can be recorded in personal life track, and automatically generate travel notes, of course, can use it to generate line design and product introduction. And then in the virtual simulation teaching system to display student line products, and its evaluation and modification.

The reform of this classroom teaching method is based on the virtual reality system integration performance foundation, at the same time under the guidance of the advanced education and teaching philosophy, the curriculum has the overall teaching design, and can skillfully run a variety of modern 
information technology, which There is no doubt that the teachers put forward higher requirements.

\section{The application of virtual reality technology in the course of practical training}

The most important features of virtual reality technology are multi-perception, immersion, real-time and interactive. The virtual software comes with interface functions such as "knowledge points", "learning materials", "exercises" and "recording" Can help students complete the course learning, training and curriculum assessment and other links.

The system comes with the "recording" function, for example, if the teacher in the course of the scenic spots on the line processing there are new requirements, you can according to the actual needs of teaching, the software in the tour line manually recorded, this time, you need to use the "record" operation interface. Manual recording path method is mainly used to record some of the smaller scenic spots, scenic spots, including relatively small. Through manual recording, the small scenic spots in the main series of static attractions together to form a dynamic tour of the line, to facilitate students in-depth understanding of a scenic area. For example, the Dujiangyan scenic two Wang Temple, from the Heap Park, etc. can use the manual recording line method. Manual recording method can also achieve a $360^{\circ}$ automatic rotation of the landscape display, such as the Dujiangyan area Fulong Temple, Wotie, Erwangdian and other attractions can be recorded using this method. In addition, you can also manually record the path of the method; the recording area between the convergences of the tour route, through this method can help students understand the real conditions of the guides to guide visitors to visit the specific lines, to enhance students in the training of the main Immersion and experience.

With the computer technology and mobile phones, IPAD and other mobile terminal technology innovation, the extensive use of modern information technology and teaching activities is the trend of modern teaching, and many of the use of virtual simulation technology to develop high-quality services to the teaching, Who are accustomed to the past simple teaching state, any investment should look at whether there is a reciprocal of the practical value, although at this stage of the virtual simulation teaching system of its high cost of investment and teaching effectiveness of the "cost ratio". There are still a lot of problems in the use of virtual simulation technology, but the popularization and use of this technology in teaching activities is a general trend, and the change of ideas and consciousness brought to the users is of great value.

\section{CONCLUSION}

With virtual reality technology as the representative of modern information technology into the vocational school and training environment, stimulate the teaching methods and means, skills training system reform. The author believes that to make effective use of virtual reality technology in teaching, it is necessary to enhance teachers 'consciousness of using modern information technology, integrate virtual reality technology into curriculum design, and strengthen students' skill training through interactive function of virtual reality system. Repeated experience in the process of strengthening the core professional skills, thereby enhancing the learning effect.

\section{REFERENCES}

[1] Zhang Xunhong, Su Jianming, Hu Qingxi, virtual reality technology in urban planning and simulation applications, computer simulation, 2003, Volume 20, No. 7 (In Chinese)

[2] Xie Weijie, the broad prospects of virtual reality [J], Earth Information Science, 1999, (2): 38-42 (In Chinese)

[3] Meng Xiangzeng, Introduction to modern educational technology [M], Jinan: Shandong University Press, 2011 (In Chinese)

[4] Liu Jinqiao, the use of FLASH courseware to improve the quality of tourism geography classroom teaching $[\mathrm{J}]$, curriculum education research, 2013,7: 156-157 (In Chinese)

[5] Zhu Xiaohua, Lu Guonian, Wang Jian, virtual reality technology in the application of geography, geography and land research, 1998, Volume 14, No. 3 (In Chinese)

[6] Yu Zhiwen, Ye Shengtao, Modern Cartography and Virtual Reality, Sichuan Surveying and Mapping, 2002, Vol.25 (No.3) (In Chinese)

[7] Gu Chaolin, Duan Xuejun, "Digital City" and its three-dimensional representation technology, Geographical Research, 2002, (1): 14-24 (In Chinese)

[8] Wang Ting, Cheng Wei, the task of teaching in the "China Tourism Geography" teaching the use of tourism, monthly survey, 2016 (3) (In Chinese) 